\title{
ASPECTOS FONÉTICO-FONOLÓGICOS E MORFOSSINTÁTICOS NO ENSINO DA LÍNGUA PORTUGUESA
}

\author{
Jefferson Evaristo do Nascimento Silva Alves (IFF) \\ Marcia Gama da Silva Felipe (UERJ)
}

RESUMO: Este texto pretende refletir sobre algumas questões que envolvem variação e mudança linguística, com implicações diretas no ensino de Língua Portuguesa. A dimensão social da língua promove uma diversidade linguística característica em qualquer nação. A reflexão que aqui propomos gira em torno de dois fenômenos de variação linguística bastante recorrentes na oralidade, uma no âmbito dos aspectos fonético-fonológicos, outra no âmbito da morfossintaxe, cuja realização, típica da modalidade oral da língua, apresenta reflexos no texto escrito. Assim, pretendemos demonstrar que tais ocorrências são recorrentes e, nesse sentido, devem apoiar um ensino analítico-crítico da língua portuguesa, contribuindo para a formação de um aluno reflexivo sobre sua própria prática.

Palavras-chave: Variação; Mudança; Aspectos fonético-fonológicos; Aspectos morfossintáticos.

Abstract: This article intends to reflect on some issues that involve linguistic variation and change, with direct implications for the teaching of Portuguese. The social dimension of the language promotes a linguistic diversity characteristic of any nation. The reflection that we propose here revolves around two phenomena of linguistic variation quite recurrent in orality, one in the scope of phonetic-phonological aspects, another in the scope of morphosyntax, whose realization, typical of the oral modality of the language, presents reflections in the written text. Thus, we intend to demonstrate that such occurrences are recurrent, and, in this sense, they must support an analytical-critical teaching of the Portuguese language, contributing to the formation of a reflective student with his own practice.

Keywords: Variation; Change; Phonetic-phonological aspects; Morphosyntactic aspects. 


\section{PALAVRAS INICIAIS}

Creditada a Ferdinand de Saussure, a divisão dos estudos linguísticos propõe abordagens diferentes do material linguístico: a sincrônica e a diacrônica. A primeira tem como objetivo a descrição da língua em determinado momento, limitado ao tempo e ao espaço. Nessa perspectiva, pode-se observar o fenômeno da variação linguística provocado por diversos fatores linguísticos e extralinguísticos. A segunda é centrada no estudo através do tempo, com a observação das modificações ocorridas, possibilitando uma visão histórica da língua. Ambas as abordagens são importantes para o conhecimento profundo das modificações pelas quais passa o código linguístico. Conhecer esse processo contribui para a formação do profissional docente, a fim de que possa perceber as nuances da língua, além dos fatores que contribuem para os fatos linguísticos que estão refletidos nos textos dos discentes.

São diversasascausasque contribuem para atransformação da língua de um povo. De modo amplo, podemos dizer que as razões sociocomunicativas são as que mais bem explicam essa mudança. O neologismo, por exemplo, pode ser consequência de uma palavra oriunda de língua estrangeira, adaptada ao idioma nacional, ou dos conhecidos processos 
de formação de palavras na língua portuguesa, fruto da criatividade humana. Seja qual for a forma de manifestação, a causa é sempre única: a necessidade de expressão, de comunicação e de representação da realidade.

Conforme observado pelos pesquisadores, as mudanças linguísticas são paulatinas, graduais e obedecem a certo encadeamento, não há uma mudança brusca. Por isso, muitas alterações só são observáveis a partir da análise diacrônica calcada na etimologia da palavra.

No presente texto, trataremos de dois temas: o primeiro versará sobre alguns fenômenos fonético-fonológicos; o segundo tratará de alguns fenômenos morfossintáticos. Desses dois campos de estudos, trataremos dos metaplasmos ou "acidentes fonéticos", conforme nomeia Serafim da Silva Neto, e destacaremos a variabilidade na concordância de número observada entre o verbo e o sujeito da oração.

Ressaltamos que os exemplos que apresentamos neste texto ou são parte integrante dos textos dos autores referenciados, ou foram elencados de produções de texto de alunos do Ensino Médio de uma escola pública estadual na periferia do Rio de Janeiro.

\section{FENÔMENOS FONÉTICO-FONOLÓGICOS}

Devido à origem da Língua Portuguesa na modalidade oral do Latim, são observadas muitas modificações na 
pronúncia, registradas pelos estudos diacrônicos da língua, na passagem de uma língua à outra. As transformações no âmbito da Fonologia podem ser exemplificadas com o desaparecimento do traço da quantidade nos sons vocálicos e com o surgimento dos fonemas palatais. A duração da vogal consistia em traço distintivo no latim entre vogal breve - representada na escrita pela braquia ( ă ) - e vogal longa, representada pelo mácron ( $\bar{a}$ ). Um exemplo dessa distinção é a diferença entre mălus (com "ă" breve) e mālus (com "ā" longo). Com diacríticos diferentes, o primeiro sinaliza a brevidade na pronúncia, apresentando o significado maçã; o segundo, com o diacrítico referente a uma maior duração na pronúncia, tem o significado de mal. Contudo, a distinção proveniente da duração na pronúncia não se manteve no Português.

Os estudos de Serafim da Silva Neto (1976), no âmbito da Fonologia histórica, abordam questões como o vocalismo, o consonantismo e os metaplasmos, dos quais destacamos o terceiro.

Os metaplasmos, chamados pelo autor de "acidentes fonéticos" (SILVA NETO, 1976, p.172), são fenômenos fonéticos que, originados na pronúncia, incidem na estrutura mórfica dos vocábulos e se refletem na forma escrita da 
língua. Por conseguinte, é comum que os professores de Língua Portuguesa encontrem no texto escrito de seus alunos os reflexos dessa pronúncia.

Estamos diante de duas características inerentes ao fazer linguístico: a variação e a mudança. Resta aos profissionais docentes desenvolverem estratégias que possam lidar com essas ocorrências, evitando as polarizações entre o ensino normativo estrito e a política do "vale tudo" linguístico.

Decorrentes do acréscimo, subtração, troca ou permuta de fonemas, os metaplasmos são fenômenos frequentes na realização linguística. Os acréscimos de fonemas são classificados como: prótese, epêntese e paragoge, quando realizados, respectivamente, no início (lembrar > alembrar), no meio (advogado > adevogado) e no final do vocábulo (cantar > cantare).

Longe de ser um exemplo que figura apenas na história pregressa da Língua portuguesa, esses fenômenos são bastante recorrentes nos dias de hoje. Dos fenômenos identificados anteriormente, destacamos dois exemplos de epêntese encontrados em textos de alunos, conforme falado inicialmente.

1) Corrupição em lugar de corrupção;

2) Apóis em lugar de após. 
O desafio que enfrentamos como professores de Língua portuguesa diante dessas ocorrências é, antes mesmo de proceder à correção de acordo com a padronização da língua, identificar a razão que levou o aluno à tal pronúncia e, consequentemente, à grafia apresentada. Os casos de epêntese exemplificados podem ser então justificados.

Na primeira forma, "corrupição", encontramos um tipo específico de epêntese de nome suarabácti. Segundo Simões, dá-se o nome de suarabácti quando a "inserção é o desenvolvimento de uma vogal no interior de um grupo de consoantes" ( 2006, p.39). Encontramos explicação dessa ocorrência na estrutura silábica do vocábulo em Língua portuguesa, cuja base de formação é a vogal. Fato é que não encontramos sílaba em nosso idioma com apenas uma consoante ou uma semivogal. Observemos que os falantes buscam apoio vocálico em todas as ocasiões em que há ocorrência de uma consoante dita "muda" (desapoiada). Não será muito de se espantar se encontrarmos formas como "caraquiterística", em que foram acrescidas três letras - "qu" para suprir o fonema consonantal /k/, representado pela consoante [c] na forma "característica, e a vogal [i], justificando a base vocálica da sílaba em questão - para suprir o fonema representado pela consoante " $c$ " em "característica". 
O exemplo de número 2 apresenta a forma "apóis". A ocorrência de uma semivogal provoca a formação de um ditongo /oy/. Não podemos perder de vista o contexto de realização do exemplo em questão: um município da periferia do Rio de Janeiro. Ou seja, nessa região, a pronúncia típica da consoante [s] em coda silábica é o som palatalizado, soando como o $[\mathrm{x}]$ de xícara, por exemplo. Essa informação é importante em função da realização articulatória dos fonemas que pode redundar em uma pronúncia diferenciada de uma região para outra sem, contudo, produzir distinção de sentido. Segundo Simões,

as consoantes participam dos fenômenos da alofonia e da neutralização. A alofonia (ou variação alofônica) decorre ora do contexto fônico, ora da pronúncia do falante; e o arquifonema é a solução técnica para a representação daqueles fonemas (os travadores) de uma forma generalizante. (2006, p.36)

Nessa citação, a autora remete à posição de travador silábico desempenhado pelas consoantes $L, R$ e $S$ que, pelos motivos anteriormente referidos, são denominados arquifonemas. Nossa intenção, no entanto, é chamar a atenção para o ponto de articulação - com pronúncia típica da região em tela - que produz resultados na grafia da palavra. Para proceder à pronúncia palatalizada do $[s], o$ 
referido falante precisa aproximar o dorso da língua ao véu palatino. Essa posição favorece o aparecimento do fonema semivocálico /y/, cuja articulação tem localização próxima à do fonema $/ \mathrm{s} /$.

Comparemos as palavras paz, pais e após. Na região em referência, a pronúncia do $[s]$ final ocorre mediante o mesmo processo articulatório, com a pronúncia do fonema /J/. O fenômeno da epêntese ocorre tanto em paz, quanto em após. Ressaltamos que essa ocorrência pode não ter incidência em regiões cuja pronúncia da consoante [s] em posição de travamento silábico seja equivalente a um fonema alveolar /s/ - conforme pronúncia corrente em São Paulo e Minas Gerais, por exemplo, dificultando, dessa forma, o aparecimento de som vocálico epentético na oralidade.

Os metaplasmos efetivados a partir da subtração de fonemas são classificados como: aférese, síncope, apócope e crase. Os três primeiros fenômenos são referentes à supressão de fonema, respectivamente, no início (obrigada $>$ brigada), no meio (fazendo > fazeno) e no final do vocábulo (cantar > cantá). A crase, por sua vez, é a aglutinação de dois sons vocálicos iguais, transformando-os em apenas um. Essa ocorrência foi bastante recorrente na passagem do Latim para o Português, em palavras que, na evolução fonética, 
apresentavam duas vogais idênticas seguidas (ex.: colore > coor > cor ; dolore > door > dor). Já na Língua Portuguesa, a crase tem ocorrência na sintaxe, no âmbito da frase, decorrente do encontro da preposição $a$ com o artigo $a$ ou com o pronome a. Encontro esse sinalizado com o acento grave, indicativo de crase - tema para uma outra ocasião.

Interessa-nos destacar no momento a apócope, bastante frequente nas salas de aula. A omissão do travador final /r/ dos verbos no infinitivo, na modalidade oral da língua: / fal'a/ em lugar de /fal'aR/, /veNd'e/ em lugar de /veNd'eR/ é bastante recorrente. Vale ressaltar que a apócope é fenômeno recorrente em todos os anos de escolaridade, tanto na modalidade oral, quanto na escrita. No entanto, quanto à pronúncia de falantes de classes sociais com maior nível de escolaridade, sua ocorrência está limitada, especialmente, a momentos de interação marcados pela coloquialidade; em que se observa um menor cuidado com a pronúncia. É comum encontrarmos exemplos como:

3) "Dá tristeza só de escreve essa carta".

Os verbos no infinitivo são confundidos com os conjugados na terceira pessoa do singular. Porém, é importante destacar que tais ocorrências não são específicas de uma língua ou uma época determinada. Pelo contrário, eles são inerentes 
ao fazer linguístico em qualquer tempo, em qualquer idioma. Contudo, embora frequente na oralidade, tal ocorrência pode resultar em confusão na compreensão do que se quer dizer, especialmente no texto escrito. Uma vez que, na modalidade oral, a tonicidade identifica o vocábulo a que se está referindo (no caso do infinitivo, com incidência na última sílaba).

\section{FENÔMENOS MORFOSSINTÁTICOS}

Alguns fenômenos morfossintáticos da Língua Portuguesa do Brasil (PB) são creditados a duas origens. A primeira está relacionada a um processo de crioulização na formação do PB. A segunda defende a herança do português europeu não padrão. Da primeira vertente, destacamos os estudos de Serafim da Silva Neto e Dante Lucchesi. Da segunda, traremos a contribuição de Antony Julius Naro e Marta Scherre, que defendem a tese da ancianidade do PB. Não entraremos no mérito da origem dos fenômenos, que fundamenta a divisão mencionada nem na defesa de uma ou outra abordagem. Deter-nos-emos na apresentação dos fenômenos morfossintáticos com base nos dados apresentados por Naro e Scherre em sua obra Origens do Português Brasileiro (2007). Naro e Scherre identificam algumas características morfossintáticas que denotam a concordância variável no 
Português europeu moderno que também são observadas no Português popular brasileiro.

A despeito das duas posições em torno da origem da variabilidade na concordância do Português brasileiro: decorrente de um processo de crioulização ou herança do Português europeu, interessa-nos aqui destacar as incidências dessa variedade na realização linguística oral e escrita nas salas de aula de Língua Portuguesa.

Segundo Naro e Scherre, a variabilidade da concordância de número é regida por diversas restrições linguísticas, dentre as quais destacamos três: a) posição relativa e linear do núcleo do sujeito dentro do sintagma (no tocante à concordância nominal), b) saliência fônica entre a conjugação verbal da terceira pessoa do singular e a terceira pessoa do plural maior saliência, maior concordância - e c) distanciamento ou proximidade entre verbo/sujeito.

Em relação à concordância nominal, os autores afirmam que o contexto de enunciação influencia significativamente na ausência da concordância. No âmbito do sintagma nominal, a posição de elemento não nuclear à direita do núcleo contribui para a não concordância de número, conforme exemplos a seguir.

4) "Aquelas cruzinha toda"; 
5) "Umas casinha bonitinha";

6) "Eles todo" / "eles mesmo".

Nos exemplos 4 e 5, os elementos à esquerda do sintagma nominal apresentam a marca de plural (s), já nos elementos à direita do núcleo a concordância é zero. No exemplo 6, o núcleo, posicionado à esquerda do sintagma, apresenta a marcação de plural (diferentemente dos exemplos anteriores). Já os elementos à direita desse núcleo não mantiveram a mesma marca.

Naro e Scherre concluem que a posição mais à esquerda do sintagma nominal favorece a marcação de concordância. Diferentemente disso, as demais posições não são favoráveis. Contudo, os pesquisadores consideram que apenas a posição linear não é suficiente à determinação de marcas formais de plural. Para eles, o fenômeno da concordância de número decorre de uma combinação de fatores como posição/classe/ relação entre os elementos do sintagma nominal.

A saliência fônica (NARO e SCHERRE, 2007, p.100-103) diz respeito à diferente marcação da tonicidade entre as formas verbais da $3 \underline{a}$ pessoa do singular em relação à $3 \underline{a}$ pessoa do plural. Os autores dizem que a baixa saliência fônica entre essas formas verbais é fator importante na ausência da concordância verbal. A baixa saliência fônica 
ocorre majoritariamente nas formas verbais que apresentam som nasal. Ocorreria uma espécie de neutralização entre as duas pessoas (singular e plural) devido a um processo de desnasalação, fator determinante na ocorrência de fenômenos que levam à não concordância da forma verbal com o sujeito. Com esse processo de desnasalação, podem surgir três configurações de concordância, conforme exemplos a seguir (2007, p.100-101):

7) Perda da consoante nasal, igualando à 3 a pessoa do singular;

Ex.: Ele come / Eles come.

8) Perda da consoante nasal e da vogal final, também igualando à 3ạ pessoa do singular (no Subjuntivo);

Ex.: Quando ele comer / Quando eles comer (em)

9) Origem de uma deformação na desinência verbal, reduzindo a terminação "am" a "o".

Ex.: Eles comeram / Eles comero

Ex.: Eles punham / Eles punho

No tocante à posição do sujeito em relação ao verbo (NARO e SCHERRE, 2007: 95-99), Naro e Scherre concluem que o sujeito à esquerda do verbo favorece a marcação explícita de plural. Fenômeno oposto ao que é observado 
quando esse posicionamento ocorre à direita do verbo. Ou seja, o sujeito posicionado à direita do verbo tende a não apresentar a marca de concordância.

10) É os home que puxa a carroça;

11) Foi os presos pra cadeia;

12) Os preso foi pra cadeia.

Em resumo, Naro e Scherre afirmam que a posição à esquerda atua no sentido de favorecer a presença de marca de plural. Na concordância verbal, o sujeito à esquerda do verbo favorece a presença de marcas; na concordância nominal, os elementos mais à esquerda do sintagma evidenciam marcas explícitas de plural.

\section{CONSIDERAÇÕES FINAIS}

Os fenômenos fonético-fonológicos e morfossintáticos elencados em nossas considerações demonstram a variabilidade inerente à linguagem. A observação dessas ocorrências deve refletir, necessariamente, no processo de ensino e aprendizagem para que possamos desenvolver a análise crítica da Língua Portuguesa, com a contribuição dos estudos descritivos.

Com essa visão, a Base Nacional Comum Curricular (BNCC) apresenta diretrizes para um ensino profícuo da língua portuguesa, calcado numa abordagem analítico-crítica, 
distanciando-se da noção de certo/errado, que tomam como referência a modalidade padrão da língua. $O$ documento visa à formação de alunos que saibam analisar o material linguístico, articulando-o com a realidade cotidiana. Em função dessa abordagem, ressaltamos que o tratamento dos aspectos fonético-fonológico e morfossintático no ensino de um idioma vai além das questões puramente prescritivas.

Vale ressaltar que o referido documento é parâmetro para um grande território, com grande diversidade em todos os sentidos. Existem aqueles que defendem uma unidade, a despeito das diferenças internas e externas ao território brasileiro. Como tratar essa diversidade, dentro do território brasileiro? Uma pessoa fala de modo diferente de outras, assim como a mesma pessoa não fala do mesmo modo, o tempo todo. São inúmeros fatores que incidem na produção linguística promovendo as variedades que conhecemos: diatópicas, diastráticas, diafásica e ainda as variedades diamésica, diageracional, diagenérica (ou diassexual) conforme Henriques (2019, p.109). No entanto, a estrutura que subjaz a essa variedade é única.

Vale destacar a opinião de Serafim da Silva Neto nesse sentido. Segundo ele, "unidade não é igualdade", o que se observa na língua portuguesa é o "princípio da unidade na 
diversidade e da diversidade na unidade" (Apud HENRIQUES, 2019, p.109). Nesse campo variado de produção linguística, vale lembrar a fala do imortal Evanildo Bechara que assevera que o ensino da língua portuguesa deve permitir que o falante seja "um poliglota na própria língua". Ou seja, além da apreensão das variedades existentes e da capacidade de utilizá-las para expressão, interação e para a atuação no mundo, o indivíduo precisa ser capacitado a usar a variedade padrão da língua a fim de alcançar os objetivos comunicativos e a inserção social, inerentes à prática linguageira. Por isso, o conhecimento das variedades linguísticas, dentre elas a norma padrão, consiste em ferramenta necessária à inserção social e ao exercício da cidadania.

Um aspecto fundamental da consciência dessa realidade linguística é que percebemos com maior clareza algumas produções de alunos em fase de alfabetização ou de alunos semialfabetizados, bastante representativas de mudanças morfofonêmicas e morfossintáticas. Por isso, necessitam de uma visão cuidadosa por parte do professor, sem que sejam tratadas indistintamente como erro. A visão da língua como resultado de interações sociocomunicativas e o conhecimento teórico aprofundado oferece instrumentos de análise ao professor permitindo que melhor oriente seus alunos no aprendizado da modalidade escrita da língua. 
Por isso, a necessidade das abordagens sincrônica e diacrônica na formação docente, especialmente, dos professores que atuam no primeiro segmento do Ensino Fundamental denota urgência. A necessidade de ambas as abordagens decorre do fato de que, numa visão sincrônica da língua, os metaplasmos, por exemplo, podem ser considerados apenas um problema linguístico, visto que destoam da norma padrão vigente.

\section{REFERÊNCIAS}

HENRIQUES, Claudio Cezar (2019). Geo-História do Português: estudos sobre a história e a geografia do português na perspectiva brasileira. Rio de Janeiro: Gramma.

NARO, Anthony Julius; SCHERRE, Maria Marta Pereira (2007). Origens do português brasileiro. São Paulo: Parábola Editorial.

SILVA NETO, Serafim (1976). Introdução ao estudo da filologia portuguesa. Rio de Janeiro: Grifo.

SIMÕES, Darcilia (2006). Considerações sobre a fala e a escrita: Fonologia em nova chave. São Paulo: Parábola Editorial.

Jefferson Evaristo do Nascimento Silva-Alves é Doutor em Letras Neolatinas e Doutor em Língua Portuguesa. Mestre em Letras Neolatinas. Professor do IFF (Instituto Federal Fluminense), atuando no ensino médio e na graduação em Letras. É coautor de diversos livros sobre ensino de Língua Portuguesa e organizador do CONELP - Congresso Internacional de Ensino de Língua Portuguesa. Participa nos seguintes grupos de pesquisa: (i) Descrição e Ensino de Língua: pressupostos e práticas, (ii) Leitura, Produção Textual e Reescrita no Ensino Médio, e (iii) Núcleo de Estudos Culturais, Estéticos e de Linguagens.

E-mail: jeffersonpn@yahoo.com.br 
Márcia da Gama Silva Felipe é Doutora em Língua Portuguesa (UERJ), Professora de Redação Acadêmica (UERJ) e Professora de Língua Portuguesa e Literatura brasileira (SME/RJ-SEEDUC/RJ). Membro do grupo de pesquisa Semiótica, Leitura e Produção de textos (SELEPROT), da Asociación de Linguística y Filología de América Latina ( $A L F A L$ ) e da Associação Internacional de Linguística do Português (AILP). Desenvolve pesquisa nas seguintes temáticas: semiótica, leitura e produção de texto e uso da literatura no ensino da Língua Portuguesa.

E-mail: prof.marciadagama@gmail.com

Recebido em 9 de julho de 2020 Aprovado em 13 de agosto de 2020 